\title{
Method development: Crystalline rock porewater extraction using vacuum-distillation
}

\author{
NAJEM, T. ${ }^{{ }^{*}}$, ZAL, D. ${ }^{1}$, KENNELL-MORRISON, L. ${ }^{2}$ AND \\ CLARK, I.D. ${ }^{1}$ \\ ${ }^{1}$ Department of Earth and Environmental Sciences, University \\ of Ottawa, Ottawa, ON, Canada \\ (*correspondence: thaje098@uottawa.ca) \\ ${ }^{2}$ Nuclear Waste Management Organization, Toronto, ON, \\ Canada (1kennell@,nwmo.ca)
}

Knowledge of the geochemical and isotopic composition of groundwater and porewater residing in the inter- and intragranular pore-space is important for determining potential flow pathways, origins, and evolution of fluids, as well as estimates of residence time. Within the context of the deep geological repository (DGR) for hosting radioactive waste, such information is important for assessing the suitability of the proposed host media from a safety perspective. Therefore, developing and demonstrating reliable methods to extract and characterize porewaters from different media is of critical importance. Vacuum-distillation is a method demonstrated to have the ability to extract porewaters from low water content and low permeability materials, and to have produced useful stable isotope and geochemical data.

With R\&D support from the Nuclear Waste Management Organization (NWMO), a new approach to extract porewater from crystalline whole-core samples was developed at the University of Ottawa. As part of this program, stainless-steel chambers were constructed to house and seal whole crystalline cores and fitted to a vacuum line for porewater extraction. The methodology was bench-tested using crystalline cores re-saturated with water of known isotopic composition under standard pressure and temperature. Full recovery of the porewater was possible within an extraction period of 6-7.5 hours at a temperature of $150^{\circ} \mathrm{C}$. Despite the full recovery, the water was depleted with respect to the stable isotopes ${ }^{18} \mathrm{O}$ and ${ }^{2} \mathrm{H}$ when compared to that of the reference water (potentially due to diffusional fractionation of the isotopes during saturation). Therefore, new saturation methods were developed and tested to eliminate the observed depletion artefact. Of all the methods tested, it was found that core saturation under vacuum ( $45 \mathrm{mTorr})$ yielded the best results, whereby the isotopic composition of the recovered porewater was, within error, equivalent to that of the saturating water. The results show that it is possible to recover $100 \%$ of water from intact crystalline drill-cores by vacuum-distillation and that the isotopic value of the water recovered represents that of the in-situ porewater. 